\title{
Hyperglycaemia in a patient with congenital hemihypertrophy
}

\author{
N N Chan, E Warwrzkowicz, A J Isaacs
}

A 64-year-old African woman with congenital hemihypertrophy presented with a 4-month history of weight gain, polydipsia, and polyuria. She was previously well apart from surgical resection of a right-sided cerebellar haemangioma at the age of 16 . There was no family history of diabetes mellitus or endocrinopathy. She was not on steroids or thiazide diuretics. On examination, her body mass index was 32, and her right arm and right leg were significantly larger than the left (figure 1). Her blood pressure was elevated at $170 / 100 \mathrm{mmHg}$. There was no evidence of diabetic microvascular complications and cutaneous signs of insulin resistance (acanthosis nigricans) were absent.

Investigation revealed a random blood glucose of $21.6 \mathrm{mmol} / \mathrm{l}$, sodium $148 \mathrm{mmol} / \mathrm{l}$, potassium $2.8 \mathrm{mmol} / \mathrm{l}$, urea $3.4 \mathrm{mmol} / \mathrm{l}$, and creatinine $98 \mathrm{mmol} / 1$. Venous bicarbonate was $25 \mathrm{mmol} / 1$ and urine dipstix showed $4+$ glucose without protein or ketonuria. Anti-islet cell autoantibody screen was negative.

\section{Department of \\ Endocrinology \& \\ Diabetes, Chelsea \& \\ Westminster Hospital, \\ 369 Fulham Road, \\ London \\ SW10 9NH, UK \\ N N Chan \\ E Warwrzkowicz \\ A J Isaacs}

Accepted 10 March 1998

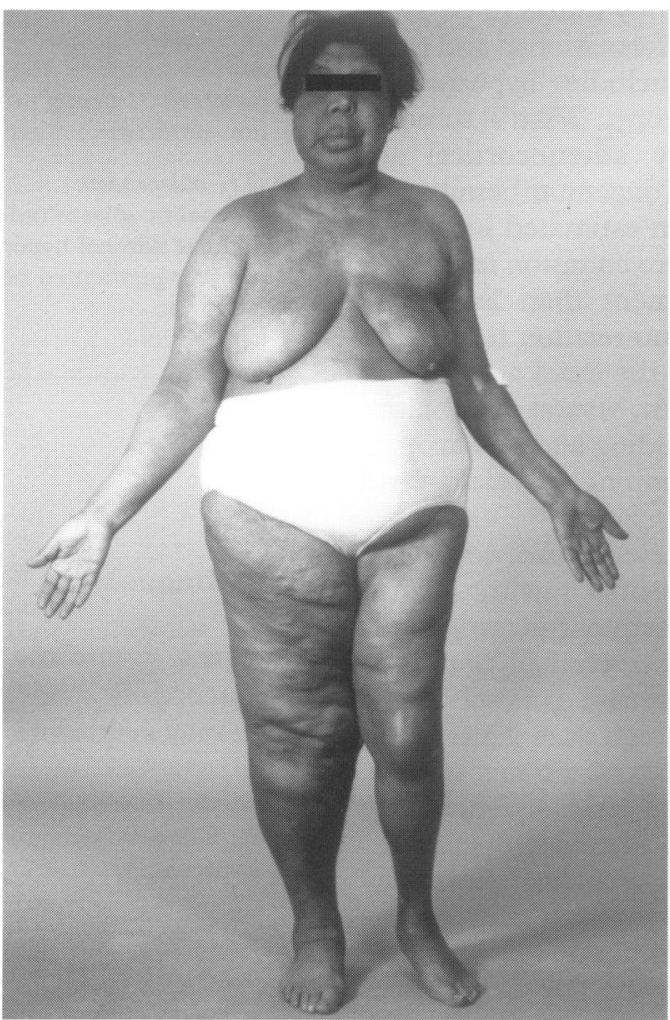

Figure 1

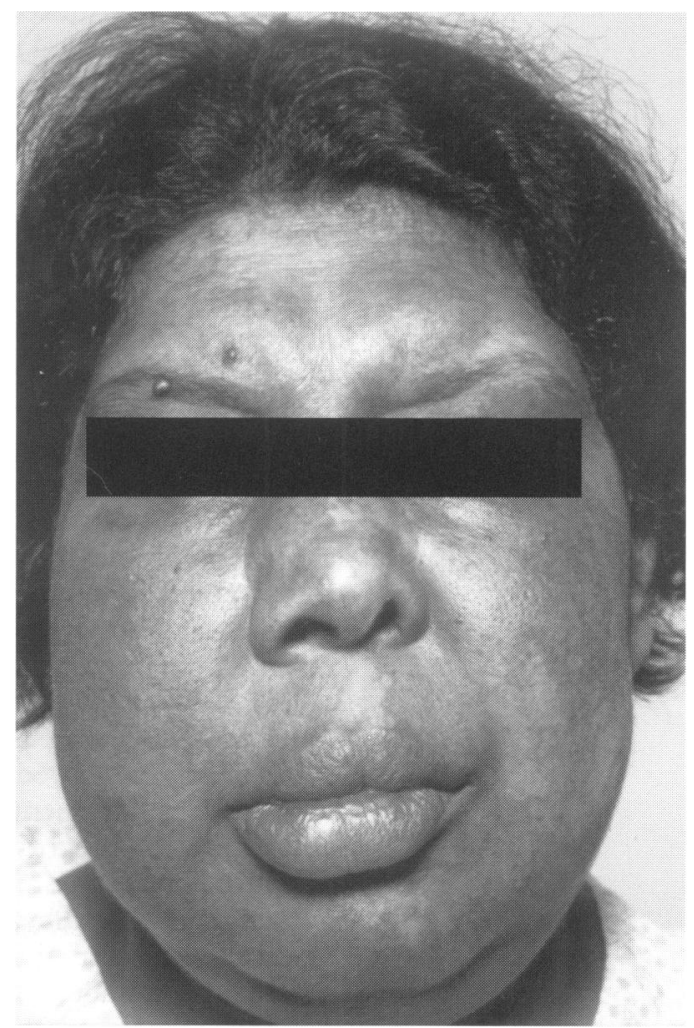

Figure 2

\section{Questions}

1 Name three other physical signs from figures 1 and 2.

2 What further investigations should be performed?

3 Which endocrinopathy(ies) is/are associated with congenital hemihypertrophy? 


\section{Answers}

QUESTION 1

Facial fullness (with asymmetry), patchy portwine stain with a diffuse distribution, and marked varicose vein of the right leg, the latter two features being characteristic of KlippelTrenaunay syndrome.

QUESTION 2

Further investigations should include determination of 09.00 and midnight cortisol, and 24-hour urinary free cortisol level, followed by low- and high-dose dexamethasone suppression tests and determination of adrenocorticotropin (ACTH) level. Once ACTHindependent Cushing's syndrome is diagnosed, computed tomography (CT) or magnetic resonance imaging will be required to localise the pathology.

\section{QUESTION 3}

Both functional and non-functional adrenocortical carcinoma and adenoma are associated with congenital hemihypertrophy.

\section{Discussion}

Congenital hemihypertrophy was first described in $1822 .{ }^{1}$ It was subsequently found to be associated with urogenital malformations, ${ }^{2}$ and renal and adrenal neoplasms, ${ }^{3}$ including hypospadias, cryptorchidism, renal ectopy, Wilm's tumour, medullary sponge kidney, adrenocortical adenoma and carcinoma. Congenital hemihypertrophy is very rare with an estimated incidence of 1 in $100000 .{ }^{4-6}$ It is more common in women with right-sided enlargement than left. $^{2}$ The associated pathology has no relation to the side of enlargement. Although the exact aetiology of this condition is not known, several possibilities have been postulated including altered chromosomal states, abnormal twinning, mosaicism and chimerism. $^{4-6}$

The patient in the present case developed symptomatic hyperglycaemia with florid Cushingoid features. Subsequent investigations revealed elevated urinary free cortisol, undetectable ACTH levels, and serum cortisol which failed to be suppressed by high dose dexamethasone. CT scan showed bilateral adrenal masses, which were subsequently resected with histology confirming adrenocortical adenoma.

The occurrence of adrenocortical pathology in congenital hemihypertrophy is well recognised although rare in adulthood. The presence of cutaneous naevus suggests the diagnosis of Klippel-Trenaunay syndrome.

1 Meckel JF. Ueber die seitliche asymmetrie im tierischen korper. In: Hale, Renger, eds, Anatomische Physiologische Beobachtungen and Untersuchungen, 1822, p147; cited by Beobachtungen and Untersuchungen, 1822, p147; cited by
Halpenn G. Normal asymmetry and unilateral hypertrophy. Halpenn G. Normal asymmetry

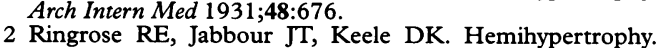
Paediatrics 1965;36:434

3 Saypol DC, Laudone VP. Congenital hemihypertrophy with adrenal carcinoma and medullary sponge kidney. Urology 1983;5:510-1.

\section{Congenital hemihypertrophy:} associated pathologies

Adrenal gland

- adrenocortical carcinoma

- adrenal adenoma

Liver

- hepatoblastoma

Kidney

- Wilm's tumour

- medullary sponge kidney

- renal ectopy

- nephromegaly

Genitalia

- hypospadias

- cryptorchidism

- penile hypertrophy

- labial hypertrophy

Others

- hamartomas

- visceromegaly

Box 1

\section{Cushing's syndrome: aetiology}

ACTH-dependent

- ACTH-secreting neoplasm

- pituitary (Cushing's disease)

- non-pituitary (ectopic)

ACTH-independent

- adrenal neoplasm (adenoma or carcinoma)

- nodular adrenal hyperplasia

- primary pigmented nodular adrenal disease

- factitious

- iatrogenic

Box 2

\section{Final diagnosis}

Cushing's syndrome secondary to bilateral adrenocortical adenoma, with KlippelTrenaunay syndrome.

Keywords: Cushing's syndrome; adrenocortical adenoma; Klippel-Trenaunay syndrome; hyperglycaemia; hemihypertrophy

4 Parker DA, Skalko RG. Congenital asymmetry: report of ten cases with associated developmental abnormalities. Paediatrics 1969;44:584.

5 Pfister RC, Weber AL, Smith EH, Wilkinson RH, May DA. Congenital asymmetry (hemihypertrophy) and abnormal disease. Pediatr Radiol 1975;116:685-91.

6 Sprayregen S, Strasberg Z, Naidich TP. Medullary sponge kidney and congenital total hemihypertrophy. NY State $\mathcal{f}$ Med 1973;73:2768. 